\title{
Failing Efforts to Mitigate Climate Change are a Futile Band- Aid that will not Stop Other Elephants Filling the Room
}

\author{
Philip Weinstein ${ }^{1}$ and Peter Daszak ${ }^{2}$ \\ ${ }^{1}$ School of Public Health, University of Adelaide, Adelaide, Australia \\ ${ }^{2}$ EcoHealth Alliance, New York
}

Much was made of the Paris Accord, an international agreement to reduce greenhouse gas emissions in an attempt to arrest global climate change, both before it spiralled out of control, and before the adverse effects on planetary and human health would be felt in earnest. Unfortunately, 20 years later, progress has been dismalmost industrial countries are still producing emissions well above the agreed targets, and many developing countries understandably are not in a position to lead on this in the absence of clear support from richer nations. As a result, we are now in a situation where interest and intervention has shifted from attempting to reduce emissions, to investing time, energy, and resources into mitigating the adverse effects of global warming instead.

To protect the world's biological resources, intervention aimed at adapting to climate change include species translocations to habitats that are predicted to become suitable as climate change progresses. To protect human populations, large-scale water management infrastructure is being built (including sea walls), desalination plants are commissioned, and air conditioning sales are burgeoning. As far as successful public health interventions are concerned, some of these measures are likely to be effective: heat-related deaths, drought- and famine-related mortality, and drowning and infectious disease deaths from flooding, in some cases will be averted-particularly in countries that

Published online: March 27, 2021

Correspondence to: Peter Daszak, e-mail: daszak@ecohealthalliance.org can afford these measures. So can we give ourselves a pat on the back that human ingenuity has solved the problem, and saves the day again?

As all of us working in public health know, particularly in the midst of the COVID-19 pandemic, fixing disasters after they happen is more costly and less effective than preventing them. Of course it is better to invest in fencing cliffs, rather than buying ambulances to deal with the people who fall off: every public health students knows that! But the social, economic, and political realities are such that there has been little to no investment in adequate fencing, which is why no significant progress has really occurred since the Paris Accord. Climate change is just one symptom of a far deeper malaise that our planet is dealing with - a decline to a future earth that may verge on uninhabitable for many of us. That decline, in our Anthropocene Era, during the 'Great Acceleration' has climate change as just one of a series of ecological insults to our planet that need critical work to reduce, wind down, and turn back (Steffen et al. 2015). This is why our current efforts to deal with climate change are no more than a band-aid, treating the symptoms of the Great Acceleration rather than the cause, and doing a poor job of even that. Band-aids on such a chronic underlying malaise are at best futile. At worst, they are a negligent misuse of our resources, and a frittering away of the critical time in which it will be possible to start reversing our decline. Indeed, they border on irrelevant compared to some of the other elephants in the room. 
Firstly and foremost, land use change is by far outstripping climate change as a driver of biodiversity loss and a steady erosion of the ecosystem services that support healthy human populations (Millennium Ecosystem Assessment 2005). Globally 6.5 million hectares of natural forest are cleared each year, predominantly in Asia, Africa and South America (Food and Agriculture Organization of the United Nations 2016). The Amazon continues to be cleared with massive fires each year, Southeast Asian rainforests continue to be decimated, and Australia and the USA still have among the highest rates of land clearing and animal extinctions in the world (International Union for Conservation of Nature and Natural Resources 2019). If we continue on this trajectory, we will lose much of the biodiversity left to be affected by climate change, so ecosystem conservation should really be given at least as high a priority as climate change mitigation, particularly when the latter has so little traction in international policy, yet garners so much media attention.

Even bigger elephants—probably a herd of mammoths in fact-is overconsumption and population growth. We are at the confluence of a multi-decadal push for globalised extraction, food production and trade that is partly driven by overconsumption in the richer countries, and by the now-unfashionable Malthusian issue of continued exponential growth in our population (Malthus 1798). This was skilfully modernised and contextualised by McMichael in his seminal work Planetary Overload (McMichael 1993), which captures the situation simply: we are on a trajectory to over-utilising our planet's resources and overpopulating our environment to a point that adverse and fatal health outcomes are inevitable. These drivers are at the heart of pandemic emergence and clearly underpin the emergence of COVID-19, which involved regions of China that are massively converted from their previous state (Rulli et al. 2020) and a wildlife farming and trade network that generated $\$ 20$ billion dollars and employed 15 million people in 2017 (Dobson et al. 2020). Our planet's population is now at 7.7 billion people (United Nations 2019), with a maximum planetary carrying capacity of approximately 10 billion if a decent quality of life is to be maintained (Smith 2015). Already somewhere in between a quarter and a third of the world's population does not have adequate access to basic food, water, education, and shelter. By 2100 the estimated global population will be 10.9 billion (United Nations 2019), with even greater pressure on the world's ecosystems, both natural ecosystems and agroecosystems. Put simply, the inability of health-giving ecosystem services to keep up with our overconsumption and population growth is likely to result in disastrous health outcomes more rapidly than will the impacts of climate change.

What are some potential solutions? Firstly, we should follow the science and public concern about pandemics, and remind the world that rapid environmental changes, driven by overconsumption, have led to the emergence of a series of high impact outbreaks, including influenza, HIV, SARS, and most likely COVID-19. As we rebuild a COVID world, we need to strengthen our economies to deal with these environmental changes, not just based on climate change mitigation incentives. Secondly, let us bring intergovernmental and national agencies working on health and environmental change together in a framework that fuses the animal-origin infectious disease focus of many One Health programs, with the more climate change and health focus of Planetary Health. Finally, we need a far greater awareness of the full scope of the Great Acceleration and its impact on our health and well-being that takes the current public drive for reduced carbon emissions into a drive for sustainability across the board. That should be our EcoHealth agenda, and we look forward to working with all of you to achieve that.

\section{REFERENCES}

Dobson AP, Pimm SL, Hannah L, Kaufman L, Ahumada JA, Ando AW, et al. (2020). Ecology and economics for pandemic prevention. Science 369:379-381.

Food and Agriculture Organization of the United Nations (2016). Global Forest Resources Assessment 2015. How are the world's forests changing? Food and Agriculture Organization of the United Nations, Rome.

International Union for Conservation of Nature and Natural Resources (2019). The IUCN Red List of Threatened Species. International Union for Conservation of Nature and Natural Resources.

Malthus TR (1798). An essay on the principle of population. J. Johnson, London.

McMichael AJ (1993) Planetary Overload: Global Environmental Change and the Health of the Human Species. Cambridge University Press, Great Britain.

Millennium Ecosystem Assessment (2005) Ecosystem and Human Well-being: General Synthesis. Millennium Ecosystem Assessment Washington.

Rulli MC, D’Odorico P, Galli N, and Hayman D (2020). Land Use Change and Coronavirus Emergence Risk. medRxiv:2020.2007.2031.20166090.

Smith P (2015) Malthus is still wrong: we can feed a world of 9-10 billion, but only by reducing food demand Proceedings of the Nutrition Society 74:187-190. 
Steffen W, Broadgate W, Deutsch L, Gaffney O, and Ludwig C (2015). The trajectory of the Anthropocene: The Great Acceleration The Anthropocene Review 2: 8198.
United Nations (2019). Workld Population Prospects 2019: Highlights. ST/ESA/SER.A/423, United Nations, Department of Economic and Social Affairs, Population Division, New York. 